\title{
Matching Problems, Precursors, and Interventions in OD: A Systemic Approach*
}

DAVID G. BOWERS

JEROME L. FRANKLIN

PATRICIA A. PECORELLA

A framework for systematic organizational development including a model for matching interventions with problem causes is developed, using concepts from social systems theory and medical science pathology. At the foundation of the framework are three basic principles of change applicable both to physical and social systems. These principles suggest that 1) interventions designed to change leadership behavior must be selected to fit properties of the system, 2) certain areas or aspects of systems are predisposed to successful change, and 3) change occurs indirectly through a series of cause/effect successions.

Potential interventions are classified in accordance with a scheme identifying each intervention according to one of three basic problem causes or "precursors." The precursors include (a) level of information, (b) level of skill, and (c) aspects of situations in which behavior occurs. Systematic organizational development is presented as a process of identifying and matching problem behavior, precursors, and appropriate interventions. Implications for practitioners are presented, along with illustrations suggesting the advantages of this approach.

* This work was supported by the Office of Naval Research, Contract N00014-67-A0181. The cooperation and help of that agency is hereby gratefully acknowledged.

David G. Bowers is a program director, Jerome L. Franklin a project director, and Patricia A. Pecorella an assistant project director, Center for Research on the Utilization of Scientific Knowledge, Institute for Social Research, The University of Michigan, Ann Arbor. 
Many have stated quite accurately that there is no general theory of organizational change and development. Nevertheless, activities abound under the general rubric of "OD." Some such activities have been generally effective and have contributed to the upgraded functioning of some of the systems they set out to help. Others have been well intentioned but generally ineffective. The reasons for the effectiveness or ineffectiveness of the various techniques may lie in the nature of the techniques themselves. That is, some techniques may simply be more effective, useful, and feasible than others, in more situations. If this is the case, the ineffective ones should be modified or discarded. Equally likely, though, is the possibility that the success or failure of any one OD activity is contingent on the "goodness of fit" between the intervention and the organizational unit in which it is utilized. Some techniques may be very effective in units experiencing certain kinds of problems created by certain conditions, while other techniques are most effective in very different circumstances. The validity of $\mathrm{OD}$ approaches may well be confounded by differential ability of organizations to choose the best intervention. Thus, the notion of "fit" between settings and interventions offers a fruitful area for exploration.

\section{THE NATURE OF CHANGE}

Change is movement, and the very nature of this concept requires that one begin with its antithesis, the steady (or homeostatic) state. Change is, therefore, some form of interruption of a preexisting steady state. Perhaps the clearest descriptions of what is involved in the change process come from the literature of pathology where an interruption of a steady state (a change) is termed a "lesion" (cf. Congdon, 1972). The occurrence of a lesion requires the coincidence of two sets of factors:

FACTORS OF REALIZATION

FACTORS OF DETERMINATION usually extrinsic occurrences which bring about the event in time, as for example the occurrence of radiation or trauma, or surgery;

usually intrinsic conditions which are necessary for the event to occur at all, as for example the structure or properties of a cell. 
Implicit in these notions is the proposition that both sets of factors are present and must in some way "match"; otherwise change will not occur. A simple medical example may illustrate this perhaps obvious point: an antibiotic drug, as a factor of realization, will produce a variety of different effects, depending upon whether the patient has (a) an infection, (b) a common cold, (c) no illness at all, or (d) an allergy to that drug. In the first instance it will likely help him; in the second and third cases it will have little or no effect, and in the final instance it may send him into anaphylactic shock. Analogyzing to the problem of organizational change and development, this implies that the change process is in all likelihood multiplex, with outcomes determined by the interaction of treatment with the condition and its etiology.

From this brief discussion we may derive what would appear to be a fundamental principle of organizational change, which we may arbitrarily label the Principle of Congruence:

For constructive organizational change to occur, there must exist an appropriate correspondence of the treatment (action, intervention) with the internal structural and functional conditions of the organization for which change is intended. Since by definition these internal conditions preexist, this means that treatments must be selected, designed, and varied to fit the properties of the organization.

Implicit in the notion of factors of determination is yet another proposition. Pathology literature states that change is most likely to occur at what are termed "sites of predilection," which ordinarily consist of points where two or more kinds of tissue meet. Atherosclerotic plaques are more common where an artery branches, for example (Congdon, 1972). The resemblance of this precept to a similar statement made by many writers in the area of organizational change is uncanny. Leavitt (1965) and many others as well talk about "entry points." Lippitt, Watson, and Westley (1958) discuss "leverage points," which may be either some strategically located unit or some functional aspect of the organization from which change may proceed to other areas. Katz and Kahn (1966) similarly seem to see change as originating (a) where the system meets its input source, (b) where system meets supersystem, (c) where echelon meets echelon. Thus, general agreement is rather apparent with what we might term the Principle of Predisposition:

There are certain points in organizational space where change will enjoy its greatest likelihood of success; these points are, at least in 
terms of the change strategy, boundary points, and change starts at that boundary and works inward.

Finally, a third proposition may be extracted by considering simultaneously the ideas of several writers and disciplines. Leavitt has distinguished between primary targets of change (those characteristics immediately impinged upon) and ultimate targets (those characteristics which are sometimes changed indirectly, through change in primary targets). From pathology come the notions of cardinality-that there are main or major processes on which other things depend, and orderthat things lead to other things. Lippitt, Watson, and Westley (1958) discuss "linkage," the idea that there must be at least a possible line of change progress from the leverage point to the change objective. The Principle of Succession is an implication of all these views:

Change is accomplished indirectly, not directly, by a process in which the intervenor changes some things in order to change other things, only ultimately arriving at the true target.

Several points emerge from all of these various conceptual statements and primitive principles. First, responsible change practice requires that one must be able to say that a particular treatment produces the condition which it is intended to produce. Yet it seems obvious that change design is not a simple matter of treatment selection-a choice of treatments whose impact is uniform whenever used. It is instead one of interaction between the treatment and the existing multidimensional conditions within the organization. Stated more simply, a particular intervention behavior or action is one thing under one set of organizational conditions and a completely different thing under others. ${ }^{1}$ The point of all this is that the change agent or designer may delude himself into believing that by using a single intervention or treatment he or she has in some sense "controlled" for extraneous factors by conducting one specific set of activities, when, in fact, precisely the opposite has occurred.

Second, one never changes "it" (the condition which one proposes ultimately to affect); instead, one changes things (makes inputs of a kind) presumed to lead to "it." Thus, we provide information, conduct skillbuilding sessions, or alter the situation because we believe that this is

\footnotetext{
${ }^{1}$ Rubin, Plovnick, and Fry (1974) support this notion in their discussion of health care systems. According to these authors strategies of change must be differentially formulated for client systems according to existing structures, norms, and values.
} 
likely to change the behavior of the persons involved. In no instance do we-nor can we-"change their behavior" directly. Only the persons involved are capable of that.

The problem of change in organizations, therefore, involves simultaneous consideration, and then appropriate sequencing across many persons, roles, and settings, of three important aspects and their potential interactions: 1) the problematic behaviors, 2) the conditions which create those behaviors, and 3) the nature of possible treatments.

\section{A BEHAVIOR CLASSIFICATION SCHEME}

Descriptions of processes and states of organizations are simply shorthand descriptions for perceived constellations of the behavior of many individuals at various points in organizational space and time. The process of formulating these shorthand descriptions involves several steps. First, one must decide which behaviors to measure and how to measure them. Once the behaviors have been measured, individual scores on the measures are averaged across persons. From these average scores, conceptual categories emerge which describe the processes and states of organizational functioning.

Two things are different, then, when one talks about organizational processes and states as opposed to when one talks about the original behavior configurations occurring in an organization. When talking about organizational processes and states: (a) a limited number of behaviors are included, and (b) a higher level of abstraction is present. These shorthand descriptions of organizational processes and states are useful for diagnostic and evaluative purposes. One can assess how an organization is functioning now (with reference to some ideal or normative score on the measures) and whether major changes are taking place in an organization, by using the measures of the processes and states as benchmarks.

However, a major goal in the OD field is to improve organizational functioning-to make interventions (alternative inputs) that add positively to the ultimate output/input ratio of the organization. Pragmatically speaking, one cannot impinge directly upon a "process." Instead one must work with specific individuals and must be able to help these individuals change the original behaviors that created the ineffective processes. Since there are neither the resources nor the time to attempt to change any or all of the original behaviors in some random order, it becomes paramount to identify some limited number of behaviors which, if changed, will cause changes in other behaviors. One should first change 
the behaviors that will eventually cause the greatest positive change in the processes and states of the organization and thereby lead to the greatest improvement in outputs. It is important, then, to have an understanding of the causal flow of events in organizational functioning so that change efforts can concentrate on the problem areas which, if changed, are likely to produce the greatest improvement.

We view leadership behaviors as prime causal variables determining the groups' processes and the system's output. According to one formulation (Bowers \& Seashore, 1966), leadership is comprised of four categories of behavior: Support, Goal Emphasis, Work Facilitation, and Interaction Facilitation (Team Building). Evidence presented elsewhere (Bowers \& Seashore, 1966; Butterfield, 1968; Taylor \& Bowers, 1972) suggests that the Four-Factor Theory of leadership is reasonably comprehensive and is related to effectiveness. While the exact nature of the influence of behaviors other than leadership on organizational processes must be explored and studied, the causal nature of leadership behavior establishes a good starting point for classifying problem behaviors. That is, by changing ineffective leadership behaviors first, one can be relatively confident that positive changes in basic organizational and group processes will occur, and that output variables will also improve.

\section{Precursors to Problem Behaviors}

As stated, a critical skill in organizational development is that of obtaining a good diagnosis of the organization, including the problems of its component parts and how they are interrelated. At base, this consists of identifying and then elaborating a definition of "organization." One of the major advances in recent years has been the development of the theories and concepts that treat the organization as a social system (Katz \& Kahn, 1966; Miller, 1971). According to this view, the social system consists of complex configurations of the behaviors of its individual members. It is therefore to a consideration of the nature and causes of such behaviors that diagnosis necessarily turns. We propose that there are four determinants of behaviors in organizational settings. These include: 1) information, 2) skills, 3) values, and 4) the situation in which individuals and groups exist. The first three can be evaluated in terms of individual organizational members. On the other hand, the situation is a more general factor associated with groups and major sub-units of organizations. Each factor can be viewed as a precursor to organizational functioning. That is, the presence, absence, and quality of each influence 
the functioning of the organization. These precursors determine the extent and type of problems that occur in the organization's processes and the variations occurring in organizational outputs.

Information. Individuals base their actions in part upon the information-including perceptions and expectations-they have acquired over time regarding what is effective or appropriate behavior. Insufficient or erroneous information about the technical aspects of the work situation results in misused and damaged equipment as well as accidents and low levels of productive efficiency. Similarly, inadequate information regarding social aspects of work situations results in wasted or injured human resources.

Erroneous models of organizational functioning based on incomplete or mistaken notions about the number and nature of critical variables together with a lack of understanding of the complexities or interactions among them can lead to widespread and severe negative consequences for the organization. A rather typical problem of this type stems from the short-range time frames used by many persons in evaluating the effectiveness of various behaviors. Many problems seem to result from notions regarding motivation based on short-term evaluations without regard for the long-range consequences. Thus, it is common to find managers who strongly believe that high production can be consistently attained through the constant application of threats and pressure, even though evaluations of such behaviors suggest that they become ineffective and quite costly to the organization after relatively short periods of organizational life (Likert \& Seashore, 1963).

Skills. Individual skills related to behavior in organizational settings also exist in both technical and social (i.e., interpersonal) areas. The ability to operate a piece of machinery or design an accounting system are examples of technical skills. Important social skills include those influencing the way organizational members interact and often are referred to as "leadership" and "group process" skills.

The distinction between technical and social skills and the importance of social skills for organizational success seem to be frequently ignored. A common assumption made by many managers is that technical skills are more vital to accomplishing organizational goals while social skills are less important. This assumption leads to the relatively large emphasis on technical training in organizations compared with training in the 
social aspects of work situations. A related assumption regarding these two skill areas is that, while technical skills require special training, social skills can be generally "picked up" by nearly anyone who has technical competencies.

Perhaps the clearest indication of this assumption is the practice of promoting individuals to managerial positions on the basis of their demonstrated technical abilities. The fact that such appointments frequently are made with little more than cursory training in management concepts-often including only an exposure to the organization's official managerial policies-in part reflects the notions that the social skills required of managers are not terribly important and are adequately acquired through minimal training and by performing in a managerial position.

A contradictory but common assumption is that social skills are essentially untrainable. Accordingly, one is either born with appropriate interpersonal competencies or acquires them very early in life, after which they cannot be altered significantly.

Experiences, observations, and research suggest that the assumptions regarding the relative unimportance of social skills in organizations, the ease in attaining those skills, and assumptions that skills are untrainable are all ill founded. The importance of social skills to organizational performance has been widely observed and is described in various formal theories (Argyris, 1962; Blake and Mouton, 1964; Katz \& Kahn, 1966; Likert, 1961, 1967). The importance of such factors has also been demonstrated through analyses of the relationship between socialpsychological aspects of organizational functioning and organizational output variables (Taylor \& Bowers, 1972). Further, the ability to train such skills has been documented by Bunker (1965) and Bunker and Knowles (1967).

Values. Every individual carries a set of values (i.e., estimations of desirability, importance, usefulness, etc.) which influence behavior. These values are related to many areas and are of varied intensities. In general, one might think of the range of intensity beginning with rather superficial opinions which are relatively unimportant to the individual, to beliefs which are more important, and finally to basic values central to the individual's self-concept and behavior. The ties that exist between values at the individual level and ideologies at the organizational level are complex and bidirectional, a point made eloquently by Miller (1971) 
and by Harrison (1972). Thus, when an individual's values foster behavior incongruent with effective organizational functioning, the consequences for the organization are likely to be detrimental. An extreme example of such a situation would be a manager whose values hold that people are relatively unimportant, expendable resources in organizations, compared to the physical plant and equipment. The behavior of such an individual could prove to be extremely costly to the organization in terms of wasting valuable human resources through turnover, lack of motivation, accidents, and psychologically triggered physical illness.

Situation. The behavior of any individual member of an organization depends in part on other individuals and groups and on the physical setting or technological requirements of the job (Davis \& Taylor, 1972). As was the case in our consideration of information and skills, we find that the situation can be evaluated in terms of both technical and social aspects.

Examples of how technology and structure influence behavior are easily identified. Machines and standardized procedures (e.g., accounting systems) generally require a limited array of behaviors. Their design dictates which behaviors are to be exhibited and in what order. For example, task design requires that a punch operator follow approximately these steps in order to accomplish the task: 1) obtain a piece of unpunched material; 2) place the material in the machinery; 3) clear one's body from the machine-sometimes with the aid of the machine, which actually pulls parts of the body away from danger; 4) operate a control to punch the material; and 5) remove the material from the machine.

Like technology, the structure of the organization has tremendous influence over individual and group behaviors within an organization. Structure greatly determines the patterns of work-related and purely social relationships found in organizations. Individuals of approximately the same status (i.e., those located at about the same level in the organizational hierarchy) and those whose work dictates that they be in close physical proximity are more likely to interact more often and in more friendly fashion than are those of greatly disparate statuses or those experiencing great physical distance.

The following examples illustrate how the behavior of each organizational member is partially determined by the combined influences of these social-psychological aspects of organizational.life. A situation might exist in which a supervisor is greatly constrained in leadership behaviors 
by the situation. If organizational policies prohibit or strongly discourage the holding of group meetings, this will have a profound and detrimental effect upon the supervisor's ability to facilitate interaction among his subordinates. Consequently, the subordinates will also be restricted in their ability to work together as a team. The result will be less effective functioning, based upon a lack of task-related interactions among members of the group.

Another example of the effects of the social-psychological aspects of the behavior of organizational members can be imagined in terms of the standard of performance established by a supervisor. In a situation in which objectives are inherently unreasonable, unattainable, or unclear, a supervisor is greatly hindered in his ability to maintain high standards of performance. In such a situation that supervisor is often placed in a position of defending the objectives rather than acting as a facilitator to the subordinates in their attempts to attain objectives.

Summary. Each of the four precursors influences the effectiveness of the individual's behavior. The most effective individuals are those who have the information and skills necessary to complete the various tasks, values congruent with effective behavior, and situations which support them in their attempts to behave effectively.

Although each precursor is important, the adequate presence and quality of different combinations of these four elements will have different consequences for the organization as well as for the individual. The consequences for organizational effectiveness depend on various factors, including the number of precursors in which widespread inadequacies exist, the number of organizational members operating with these inadequacies, and the level in the organizational hierarchy where various deficiencies are encountered. Organizational functioning suffers most when deficiencies 1) involve more rather than few precursors, 2) influence the behaviors of large numbers of organizational members, and 3) occur at high levels in the organizational hierarchy.

\section{A THREE-DIMENSIONAL MODEL OF ORGANIZATIONAL DEVELOPMENT}

The various OD techniques can be classified according to the precursor mode on which they impinge most directly and most immediately. Unlike the classification for the precursor modes, values has not been included as a category for classifying development techniques since values are not subject to direct change. Changes in values occur only as a result 
of impingement on one of the other three areas. For example, some counseling and some forms of laboratory training employed to change values are classified under the information category since these techniques primarily impinge on an individual's information.

Figure 1 presents a variety of well-known and accepted techniques classified according to the primary impingement mode of each. In addition, the figure illustrates a three-dimensional (3-D) model which should be considered to facilitate effective organizational development. ${ }^{2}$ This model contains three basic dimensions:

1. Problematic behaviors-defined herein in terms of four categories of leadership behaviors: Support, Interaction Facilitation, Goal Emphasis, Work Facilitation.

2. Conditions causing these behaviors-described as the precursors: information, skill, situation, values.

3. The nature of possible treatments-the three categories of development techniques termed impingement modes: information, skills, situation.

The model contains 48 cells $(3 \times 4 \times 4)$ each representing different combinations of the three basic dimensions. For example, the cell labeled "A" describes a problem in supportive behaviors resulting from inadequate information and rectifiable through some strategy related to informational input, such as management seminars or team development.

\section{Matching Precursor with Impingement Mode}

From the Principle of Congruence we know that problem behaviors, precursors, and impingement modes need to be matched in some systematic way. However, there are at least three possible competing interpretations of the way in which this match should occur. Each interpretation is discussed below.

Interpretation 1 . The impingement mode should always be congruent with the precursor (with the exception of values, which would be changed indirectly by affecting one or more other precursors). For example, if the source of poor work facilitation is diagnosed as lack of information, the treatment should focus on providing information-not skill training or structural modifications. This would suggest that-

2 An alternative three-dimensional model has been presented by Schmuck and Miles (1971) for the classification of OD interventions. 
When the Precursor Is:

The Impingement Mode Should Be:

\begin{tabular}{l|l}
\hline Information & Information \\
Skills & Skills \\
Situation & Situation \\
Values & (No direct impingement possible)
\end{tabular}

The match between precursor and impingement mode would not be affected by the specific nature of the problematic behaviors. For example, if members of the client system lack necessary information, the impingement mode should be information, regardless of whether the problem centers around support, interaction facilitation, goal emphasis, or work facilitation. However, the specific content of the intervention technique would be determined by the nature of the problematic behaviors. If the problematic behavior is lack of support by supervisors, the information presented, by whatever specific technique, would be information about the meaning, importance, and implications of supervisory support. It would be nonsensical to provide information about supervisory interaction facilitation, goal emphasis, and work facilitation except when this information would clarify the issues relevant to supervisory support. Thus, once the appropriate precursor has been identified, the "Problematic Behavior" dimension becomes essential for determining the content of a specific technique.

Interpretation 2. The impingement mode should be matched in some other way with the precursor. To use the earlier example, if the cause of poor work facilitation is diagnosed as a lack of information, one might change the situation, with the expectation that the indirect effects would be beneficial (e.g., moving role-related employees into closer physical proximity, thus making information sharing more likely). This would suggest that-

When the Precursor Is:

The Impingement Mode Should Be:

Information
Skills
Situation
Values

Information
Skills

Situation
Skills or Situation

Information or Situation

Information or Skills

Information, Skills, or Situation 


\section{FIGURE 1.}

Development Strategies and Techniques and the

Three-Dimensional Model of Organizational Development

IMPINGEMENT MODE

\begin{tabular}{|c|c|}
\hline Information & $\begin{array}{l}\text { Client-Centered Counseling } \\
\text { Laboratory Training } \\
\text { Management by Objectives } \\
\text { Management Seminars } \\
\text { Managerial Grid Organizational Development } \\
\text { Merger Laboratory } \\
\text { Motivation Training } \\
\text { Process Consultation } \\
\text { Scientific Management } \\
\text { Survey Feedback } \\
\text { Survey-Guided Development } \\
\text { Team Development } \\
\text { Third-Party Consultation }\end{array}$ \\
\hline Skill & $\begin{array}{l}\text { Behavior Therapy } \\
\text { Imitative Learning } \\
\text { Skill Training }\end{array}$ \\
\hline Situation & $\begin{array}{l}\text { Decentralization } \\
\text { Differentiation/Integration } \\
\text { Flow of Work } \\
\text { Job Enrichment } \\
\text { Leadership-Situation Engineering } \\
\text { Operations Research } \\
\text { Scanlon Plan } \\
\text { Sociotechnical Fit } \\
\text { Structural Change }\end{array}$ \\
\hline
\end{tabular}

\section{STRATEGIES AND TECHNIQUES}

Client-Centered Counseling

Laboratory Training

Managerial Grid Organizational Development

Merger Laboratory

Motivation Training

Process Consultation

Scientific Management

Survey Feedback

Survey-Guided Development

Team Development

Behavior Therapy

Imitative Learning

Skill Training

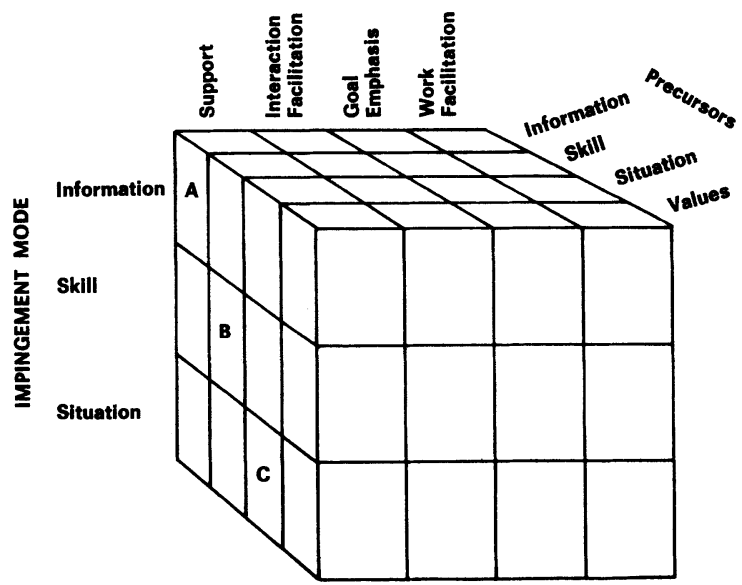


Once again the match between precursor and impingement mode would not be affected by the nature of the problematic behaviors, but the content of the specific intervention would depend upon the nature of the problematic behaviors.

If either of the above interpretations is valid, whole rows in the threedimensional model would be useful or not useful for OD. If interpretation 1 is valid, the rows labeled $A, B$, and $C$ would be the only useful rows; if interpretation 2 is valid, all rows except $A, B$, and $C$ would be useful. Quite a different (and more complex) state of affairs would exist if the third interpretation, described below, were the valid one.

Interpretation 3. Precursor, impingement mode, and problematic behaviors must be matched in some specific way. For example, if employees lack the technical skills required to help each other solve work-related problems, then provide skill training; if employees lack the interpersonal skill required to provide emotional support to one another, however, change the situation to one where people who get along well work together. If this interpretation is valid, OD would be a cell-specific (as opposed to a row) problem, with respect to the three-dimensional model in Figure 1. There would be at least 48 different states with which we might be faced. The appropriate impingement mode would have to be matched with certain combinations of precursors and problematic behaviors. If this interpretation is valid, all of the 48 possible cells would have their own "time and season" of usefulness in different OD settings.

While interpretations 1 and 2 are mutually exclusive, interpretation 3 could hold within a framework consistent with either of the other two interpretations. For example, it could be true that a skill deficiency is always best remedied by a skill training input in the specific case of work facilitation, whereas a skill deficiency in goal emphasis normally requires for its correction an information input.

Complications. A critical issue, therefore, is that of determining which interpretation is most valid. Several related issues also arise. For example, more must be known about the nature of particular precursors and problems, since some precursors and problems may be more easily "impinged" upon or be more quickly responsive to impingements than others. For instance, increasing the supportiveness of supervisors may be more difficult and take more time than improving their work facilitation. Or, changing values may take longer than upgrading skills. If these differ- 
ences are not taken into account, the most appropriate match of impingement modes to problems and precursors cannot be attained.

On the other hand, some interventions may simply be more effective than others (cf. Bowers, 1973). Taking a hypothetical case, a practitioner might apply OD technique " $\mathrm{X}$ "- an information-providing intervention-to solve a given problem in one setting, but implements technique " $\mathrm{Y}$ "- a skill-building intervention-to solve a very similar problem in a second setting. If the intervention were successful in the first setting and unsuccessful in the second, a definite question of meaning would arise. Are techniques using the information impingement mode more appropriate for solving that particular problem than techniques using the skill impingement mode, or is technique " $\mathrm{X}$ " generally more effective than technique "Y"?

The number of precursors or problems operating in a setting must also be considered. Thus far, the model has dealt with matching one problem and precursor with one intervention. When a diagnosis indicates the existence of multiple problems or precursors, however, there is a high likelihood that the various problems or precursors operate differently in combination than each operates separately-that is, they probably interact. The presence of such interactions might alter the appropriateness of various impingement modes.

\section{OD Client as Patient: Diagnosis and Treatment}

The three-dimensional model proposed is equivalent to a "medical" model, where the problem is described as the demonstrable symptom, the precursor is the underlying cause of the disease, and the impingement mode is the nature of the treatment deemed appropriate. The 3-D model necessitates a differential diagnosis that describes the nature of the disease and its causes. The nature of the treatment must be based upon the diagnosis and must be administered at the correct time and in the correct dosage.

There are, of course, dangers inherent in the application of such a model, including the risks that members of the system will reject the diagnosis, and consequently, the treatment. The process of applying such a model is critical in gaining acceptance of the diagnosis and commitment to the corrective intervention. The process requires educative and skill-building aspects to enable the client both to understand the diagnostic and prescriptive procedures and to be actively involved in them. 
The essential point is that if OD is to be maximally effective, and if different approaches to OD are to be tested empirically, it must be moved in the direction of more detailed and intensive diagnoses and more exact choices of appropriate interventions.

\section{IMPLICATIONS FOR PRACTITIONERS}

The general framework for OD presented here and the principles upon which it is based suggest some important implications for practitioners.

The Principle of Congruence teaches that-

Change activities must be matched appropriately with the nature of the problems and their causes and with the nature of the organizational units under consideration.

A systematic diagnosis of organizational conditions and practices, and individual and group behaviors should precede the selection of corrective activities. The completed diagnosis should include a description of problem behaviors and their causes.

Given the particular problem to be solved and its causes, the practitioner should decide whether it would be most effective to eliminate the cause of the problem directly or indirectly. A direct approach involves choosing corrective activities that have the same primary "target" (i.e., information, lack of skills, inadequate situation). The indirect approach, on the other hand, involves selecting corrective activities with a primary target different from the cause of the problem. ${ }^{3}$ An example involving an absence of effective teamwork may help to clarify the difference between these two approaches. Using the direct approach, an existing structure (i.e., the situation) might be changed to one that utilized work teams, thus encouraging more contact and coordination among subordinates. Using an indirect approach, supervisors might be given information about the benefits of teamwork or given skill training in encouraging teamwork. These interventions might motivate supervisors (if they know they have the support of their superiors) to change their behavior, which would eventually change the organization's structure. Choosing one approach over the other will depend partly upon the relative practicality and acceptability to members of the system of the potential corrective

3 The indirect approach must be used when a problem is caused by incongruent values, since no change techniques have a "change in values" as their primary target. 
activities called for by each of the two approaches. The choice may also be influenced by beliefs or experiences of the practitioner or system members relevant to how a change in behavior is brought about (i.e., whether to focus on changing knowledge, skills, or situation first in order to affect behavior).

The Principle of Predisposition suggests that-

Change will occur first and foremost at the following interfaces:

1. Where the system meets its input sources, culture, or society, e.g., in units where new personnel, younger, better-educated, minority persons are present in atypical numbers; or in boundary units such as sales, purchasing, personnel, research and development.

2. Where the system meets its supersystem, e.g., in top management groups.

3. Where major echelons meet, e.g., where first-line supervision meets middle management.

4. Where functionally different lines merge, e.g., at the interface between production and maintenance functions.

These statements imply that initial change attempts will be more successful in some sections of the "organizational space" than in others. Less obvious, however, is the implication that if problems at the interfaces listed above are not dealt with, change attempts in other areas of the organization are likely to be unsuccessful.

Finally, the Principle of Succession is instructive.

It is important to consider the sequence in which problems are solved and action steps implemented. Solutions should be designed to solve the problem at hand without creating new ones.

The practitioner should focus attention first on those problems which may be solved in a reasonable amount of time and which do not require resources (e.g., skills and money) that the organization would be hard pressed to obtain. This statement is based on the notion that it is important to maintain a motivating discrepancy between how an organization functions at a given time and its ideal modus operandi. Choosing a problem huge in scope requiring several months and unobtainable resources to solve would reflect too large a discrepancy, whereas settling for more manageable problems first may lessen the discrepancy enough to motivate and enable people to work on solving problems which previously seemed out of reach. 
Secondly, when more than one problem is to be solved, or when a single problem is multifaceted, special attention should be given to implementing action steps in the appropriate order. Some problems, or aspects of a problem, need to be worked on before others can be solved. Some action steps have to be taken before others can be attempted.

\section{Professionalism Before Prescribing}

As the general change framework, the 3-D model, and practitioner implications suggest, movement toward a more systematic approach to OD requires extensive knowledge and skill. Diagnosis, which includes the analysis and integration of information from individuals, groups, functional areas and hierarchical levels, is a complex process requiring extensive knowledge of organizational functioning both of a general nature and for the specific unit under consideration. In addition, great skill is required for organizing this information in such a way that it is intelligible and useful as a basis for matching and sequencing interventions to coincide with problem causes. Although the requirements of such an approach are considerable, the potential payoffs from moving OD in this direction seem worthy of the effort.

\section{REFERENCES}

Argyris, C. Interpersonal competence and organizational effectiveness. Homewood, Ill.: Irwin, 1962.

Blake, R. R., \& Mouton, J. S. The managerial grid. Houston: Gulf Publishing Co., 1964.

Bowers, D. G. OD techniques and their results in 23 organizations: The Michigan ICL study. Journal of Applied Behavioral Science, 1973, 9 (1), 21-43.

Bowers, D. G., \& Seashore, S. Predicting organizational effectiveness with a four-factor theory of leadership. Administrative Science Quarterly, 1966, 11 (2), 238-263.

Bunker, D. R. Individual applications of laboratory training. Journal of Applied Behavioral Science, 1965, 1 (2) , 131-148.

Bunker, D. R., \& Knowles, E. S. Comparison of behavioral changes resulting from human relations training laboratories of different lengths. Journal of Applied Behavioral Science, 1967, 3 (4) , 505-523.

Butterfield, D. A. An integrative approach to the study of leadership effectiveness in organizations. Unpublished doctoral dissertation. Ann Arbor: University of Michigan, 1968.

Congdon, C. C. Pathological processes (Part 1, Notes). Knoxville: University of Tennessee, 1972.

Davis, L. E., \& Taylor, J. C. Design of jobs. Middlesex, England: Penguin Books, 1972.

Harrison, R. Understanding your organization's character. Harvard Business Review, 1972, 50 (3) , 119-128.

Katz, D., \& Kahn, R. L. The social psychology of organizations. New York: Wiley, 1966. 
Leavitt, H. J. Applied organizational change in industry. In J. G. March (Ed.), Handbook of organizations. Chicago: Rand McNally, 1965. Pp. 1144-1170.

Likert, R. New patterns of management. New York: McGraw-Hill, 1961.

Likert, R. The human organization. New York: McGraw-Hill, 1967.

Likert, R., \& Seashore, S. E. Making cost control work. Harvard Business Review, 1963, 41 (6) , 96-108.

Lippitt, R., Watson, J., \& Westley, B. The dynamics of planned change. New York: Harcourt, Brace and World, 1958.

Miller, J. G. The nature of living systems. Behavioral Science, 1971, 16, 278-301.

Rubin, I., Plovnick, M., \& Fry, R. Initiating planned change in health care systems. Journal of Applied Behavioral Science, 1974, 10 (1) , 107-124.

Schmuck, R. A., \& Miles, M. B. (Eds.) Organization development in schools. Palo Alto, Cal.: National Press Books, 1971.

Taylor, J. C., \& Bowers, D. G. Survey of organizations. Ann Arbor, Mich.: Institute for Social Research, 1972.

\section{On Measurement}

... Measures of the quality of working life are a subset of measures of the quality of life. . . . We need to start with a minimal list of quality of working life attributes because the one thing that is certain in any kind of development of statistical series is that they will expand. No matter what is available someone wants something else.

...We imposed on ourselves the principle of statistical parsimony. One of the conflicts within the task force was whether to concentrate on the individual or the aggregate. There was an underlying fear that the soul of the "bloke" would escape through the punched hole in the IBM computer card. As one starts aggregating one tends to lose the individual.... 